\title{
Sociodrama e Política de Cotas Para Negros: um Método de Intervenção Psicológica em Temas Sociais
}

Sociodrama and quota policy for africanbrazilians: psychology intervention method in social subjects

Maria da Penha Nery

\& Maria Inês Gandolfo Conceição

Universidade de Brasília

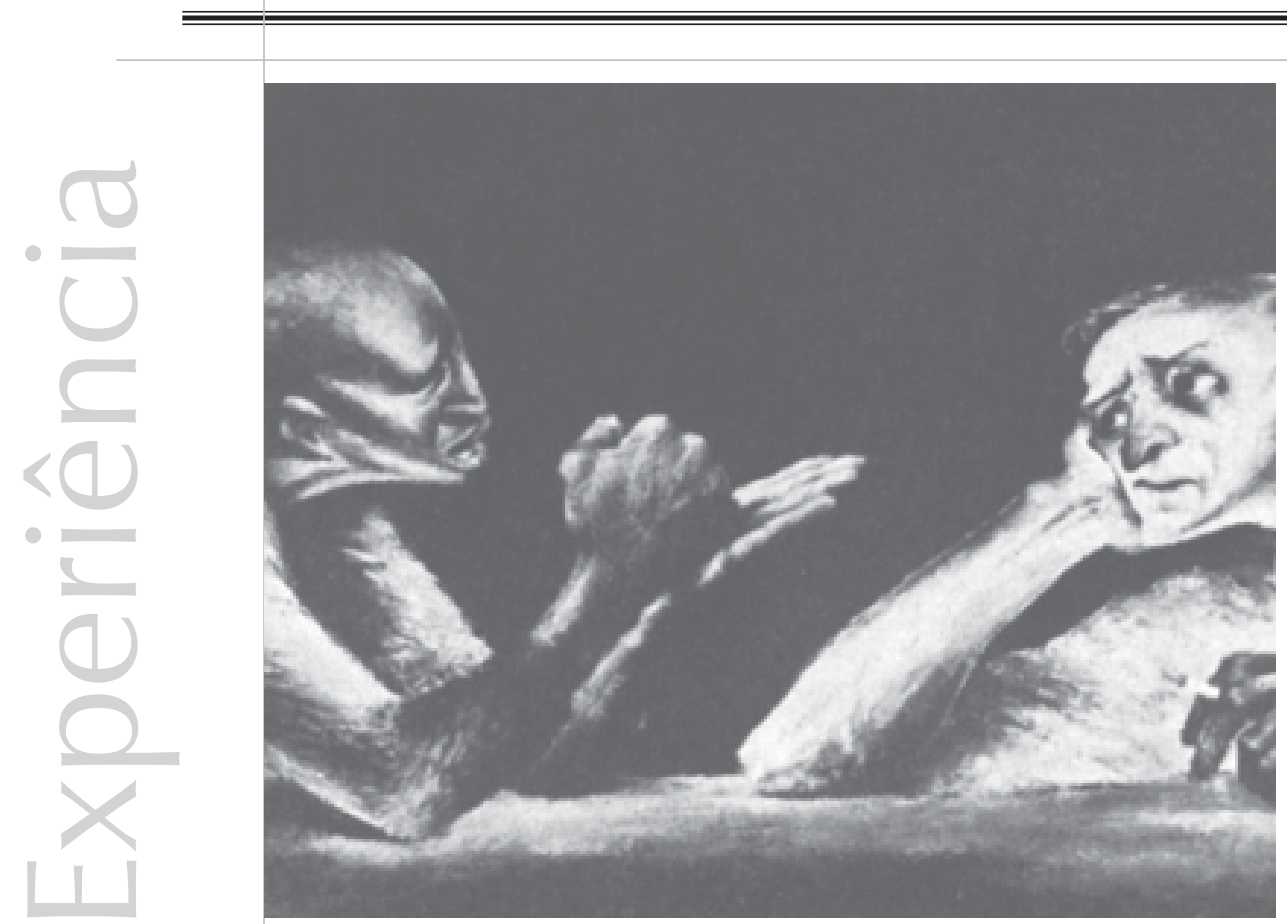


Resumo: O artigo propõe o sociodrama como método sociátrico para a atuação do psicólogo frente a temas polêmicos, dentre eles, a política de cotas para negros nas universidades. Inicia-se com uma reflexão sobre algumas produções científico-culturais que instrumentam cientistas sociais para a transformação social. Partindo do pressuposto que a mudança social, promovida por métodos culturais e psicoterapêuticos, tem, em sua base, o fenômeno da catarse, o texto aborda a evolução desse conceito: dos rituais, passa-se pelo teatro grego, pela Psicanálise, até o sociodrama, que cria a noção de catarse de integração. Exemplifica-se com um sociodrama do sistema de cotas para negros na Universidade de Brasília, realizado com estudantes de Psicologia. O evento mobilizou a criação conjunta favorecedora do processo de inclusão social e desvelou o papel político do psicólogo na sociedade.

Palavras-chave: sociodrama, sociatria, política de cotas para negros nas universidades.

\begin{abstract}
The article suggests sociodrama as a sociatric method for the actions of the psychologists when facing polemic issues, among them, the quota policy for African-Brazilians in universities. The article starts with a thought about scientific-cultural productions that assist social scientists for the social transformation. Assuming social changes through cultural and psychotherapeutic methods are based on the catharses phenomenon, the text analyses the evolution of this concept: rituals, Greek theatre, Psychoanalysis and sociodrama, which creates the idea of integration catharses. Example is given by a sociodrama of the quota system for African-descendants in the University of Brasilia, undertaken by Psychology undergraduates. The event led to a collective creation that favoured a social inclusion process and revealed the political role of the psychologist in society.
\end{abstract}

Key words: sociodrama, sociatry, quota system for African-Brazilians.

O sofrimento dos indivíduos, dos grupos e da sociedade brasileira está cotidianamente retratado nas ruas, casas, comunidade e instituições. Desigualdade social, desigualdade racial, desemprego, epidemias, corrupção, violência e drogas são apenas alguns exemplos. As ciências sociais e a Psicologia são chamadas para compreender e tratar esse sofrimento, em particular o grupal. Porém, que técnicas são usadas para intervir nos grupos? Quais os procedimentos apropriados para abordar terapeuticamente a sociedade em seus pequenos e grandes grupos? Como manejá-los? De que forma a subjetividade interfere nessa prática profissional?

Nessa perspectiva, este artigo propõe o sociodrama (Moreno,1974) como um método de pesquisa e tratamento dos grupos (sociatria) que pode ser utilizado por psicólogos e cientistas sociais. O sociodrama pertence à ciência Socionomia, criada por Jacob Levy Moreno (1974). Essa ciência estuda a articulação entre o individual e o coletivo, e é composta por três ramos: a sociodinâmica (estuda a dinâmica grupal); a sociometria (focaliza o estudo das organizações e estruturas grupais) e a sociatria (intervenção terapêutica nos grupos em sofrimento). A sociatria utiliza vários métodos sociátricos, dentre eles o psicodrama, o sociodrama, os jogos dramáticos e a psicoterapia de grupo.

O sociodrama é um método que busca compreender os processos grupais de uma situação-problema por meio da ação/ comunicação das pessoas. Proporciona-se ao grupo uma experiência específica relacionada aos temas ou conflitos que Ihe são peculiares. Nessa experiência, procura-se viabilizar - em
Partindo do pressuposto que a mudança social, promovida por métodos culturais e psicoterapêuticos, tem, em sua base, o fenômeno da catarse, o texto aborda a evolução desse conceito: dos rituais, passa-se pelo teatro grego, pela Psicanálise, até o sociodrama, que cria a noção de catarse de integração.
1 Em sociodrama, as sessões são conduzidas por uma equipe psicoterapêtica denominada "unidade funcional", que é composta por um "diretor" e um "egoauxiliar". 
cenas dramatizadas pelos participantes ou em interações direcionadas - a expressão das pessoas e suas tentativas de resolução dos conflitos.

Antes de se aprofundar no conhecimento do sociodrama, deve-se compreender de que forma a sociedade tem recorrido a meios sociais e culturais para a libertação ou para a opressão do homem. A ciência, a religião, a arte, o esporte, dentre tantas produções humanas, podem minimizar os sofrimentos da humanidade ou exacerbá-los. Foucault (1990) preconizou as práticas de poder e a construção da verdade advindas das instituições para disciplinar, controlar e vigiar o homem, tornando-o e o mantendo dócil diante das opressões e dos saberes demarcadores de padrões que suprimem a diversidade e a criatividade. No entanto, há também o belo, o conhecimento e os métodos criados por homens que resistem politicamente e que reativam valores universais, como os direitos humanos e a bioética. Trata-se da criação que ajuda a humanidade a se conscientizar ou a exprimir suas dores e, muitas vezes, a transformar crises e comportamentos que a desequilibram em aprendizados. Essa produção liberadora tem como efeito o processo catártico.

A Antropologia demonstra que os rituais religiosos e culturais auxiliam o ser humano a enfrentar situações de insegurança, de estranheza, de surpresa, de embates, e ajudam-no a manter o status quo socioeconômico da comunidade. Segundo Reñones (1996), no contexto do ritual há uma situação de passagem, concretizada pelo ciclo vida-morte-renascimento. Nessa situação, "uma nova forma de estar no mundo toma lugar de uma antiga, muito mais para ampliar o horizonte do que para castrá-lo" (p. 40). O ritual mobiliza, portanto, um processo liberador, associado ao conceito de catarse. Esse conceito evoluiu ao longo da história da humanidade, de acordo com a sua necessidade de libertação da opressão e de equilíbrio psicossociológico.

O termo Kátharsis aparece no século VIII antes de Cristo, na Odisséia de Homero. Nesse período, seu sentido era religioso e significava o processo de transformação que o iniciado passava para poder compreender as sábias profecias. Hipócrates adaptou o termo para o sentido de limpar, e Platão adicionou-lhe a questão moral de alívio da alma daquilo que devia ser lavado. A cultura latina reveste o termo catarse de significado médico e, no contexto religioso, ele se vincula às noções dadas pelas instituições cristãs - de pecado e da dualidade alma/corpo. A alma precisava ser salva por meio de uma completa limpeza das máculas produzidas pelo pecador (Reñones, 1996).

A tragédia grega trouxe uma função catártica para a humanidade pela via psíquica do processo de identificação. O protagonista resumia e agonizava a dor persistente e genérica de todos à medida que seus dramas eram refletidos no teatro. Aristóteles (1985) afirmou que a platéia se aproximava emocionalmente do ator principal, vivendo a compaixão e o terror, e refazia, nesse movimento estético, seu caminho existencial. Tratava-se de uma catarse que purgava as emoções dos espectadores ou amenizava a dor social (Moreno, 1975). No entanto, na maior parte das vezes, o efeito catártico da representação do drama grego funcionava como um anestésico, e não como um curativo. As feridas das injustiças, da corrupção e do abuso de poder permaneciam e utilizavam diversos mecanismos para resistir.

Finalmente, surgem, no cenário humano, as ciências da Psicologia e da Sociologia, que, a partir da Filosofia, contribuem para a 
compreensão dos processos subjetivos e intersubjetivos. A Psicanálise, em particular, por meio das descobertas de Freud e Breuer (Freud, 1905), desenvolve o estudo dos mecanismos intrapsíquicos e objetiva o tratamento das psicopatologias. Os métodos hipnóticos e, posteriormente, o método da associação livre, em setting e relação específicos com o psicanalista, dão origem ao fenômeno da catarse de ab-reação. Essa catarse é a expressão da (re)vivência da tragédia pessoal do analisando por meio de suas lembranças e de sua fala. A intensidade dramática vivida pelo paciente libera conteúdos reprimidos ou recalcados do seu inconsciente, curando os sintomas psicopatológicos.

Para além da Psicanálise e incorporando seus conhecimentos, a Psicologia e a Sociologia, ao enfocar o estudo das relações humanas e dos conflitos sociais, propõem outros métodos para promover novas catarses e mudanças pessoais e sociais. A literatura das ciências humanas auxilia na compreensão dos conflitos humanos, das guerras, da violência, das sociedades de classes e dos desequilíbrios psíquicos como fenômenos pertinentes à vida social. Teóricos sociais clássicos descrevem os aspectos sociopsicológicos dos conflitos intergrupais, dentre eles, Emile Durkheim, Karl Marx, Max Scheler, Georg Simmel e Max Weber, Deutsch, Festinger, Frank, Goffman, Lewin, Parsons e Sherif e Sherif.

Esses e muitos outros pensadores oferecem subsídios teóricos para a construção e o aperfeiçoamento de técnicas e métodos socioterápicos. Essas intervenções visam a que cada ser humano, usando de seus conhecimentos, personalidade e cultura, possa atualizar seu potencial terapêutico em todos os campos sociais, seja no lar, na comunidade, nas instituições, na sociedade. O cientista social deve ter a preocupação de se preparar teórica e tecnicamente para uma prática consciente que repercuta positivamente em sua profissão. Portanto, é tarefa dos cientistas sociais, em particular dos psicólogos, desenvolver os recursos socioterápicos existentes, criar novos e manejá-los adequadamente com o objetivo de auxiliar o ser humano a viver com mais dignidade.

A necessidade de tais recursos é premente no atual cenário psicopolítico-social, pois o Brasil vive um campo de combate. Basta ver as pesquisas socioeconômicas de institutos especializados, dentre eles, IPEA e IBGE. Em 1999, o Brasil apresentou um alto índice de desigualdade, medido pelo índice Gini. O relatório do IBGE afirma que a concentração da renda dos $10 \%$ mais ricos chegou a ser 60 vezes maior do que a dos $10 \%$ mais pobres, e só recuou para 47 vezes no fim dos anos 90 . O índice de desemprego é dos maiores do mundo. Por sua vez, a injustiça racial é denunciada quando apenas $2 \%$ dos pretos e pardos freqüentam as universidades, sendo que eles compõem cerca de $50 \%$ da população. No que se refere à desigualdade racial, o analfabetismo é maior e a renda é menor entre negros e pardos: a renda em salários mínimos é de 5,25 para os brancos; 2,54 para os pardos e 2,43 para os negros. $\mathrm{O}$ analfabetismo é de 8,3\% dos brancos, 19,6\% dos pardos e $21 \%$ dos pretos do País.

Segundo o IPEA (2004), 70\% do contingente que vive abaixo da linha da pobreza é negro (22 milhões no total). Dos 53 milhões de brasileiros que vivem na pobreza, $63 \%$ são negros. Segundo o IBGE (2004), 53,6\% da população jovem branca (de 20 a 24 anos) cursa o nível educacional superior; quanto aos pretos e pardos, apenas $15,8 \%$.

Essa fotografia estatística mostra que é imprescindível resgatar a convocação de Paulo
Os métodos hipnóticos e, posteriormente, o método da associação livre, em setting e relação específicos com o psicanalista, dão origem ao fenômeno da catarse de abreação. 
Freire (1976): todo profissional deve tornarse trabalhador da transformação social e possibilitar a conscientização, principalmente para os que mais necessitam de voz, dentre eles, os oprimidos e as minorias sociais e raciais. Também Foucault (1990) nos alerta que o papel do intelectual se torna importante na medida em que ele é obrigado a assumir responsabilidades políticas, independentemente de sua vontade.

O conhecimento sem posicionamento é frio, inóspito, vazio. O conhecimento pelo conhecimento é em vão. O conhecimento na via da conscientização é o primeiro passo para a transformação social. O conhecimento que fundamenta uma ação terapêutica visando à renovação da alma humana e da coletividade é vital. Por isso, torna-se imprescindível o aperfeiçoamento e o desenvolvimento de métodos de intervenção

" A cartarse promovida pelo Teatro Espontâneo é a catarse de integração" terapêutica grupal e comunitária. Quais técnicas e procedimentos dos cientistas sociais contribuem para a construção de uma cidadania digna e emancipada?

Os métodos de debates sociopolíticos são fomentados pela pedagogia e pela assistência social críticas, incrementando a democracia e aumentando a consciência política dos cidadãos que se engajam nas lutas sociais. Muitas leis impulsionadas dos movimentos sociais são propiciadoras de mais justiça social e ainda, no próprio cotidiano, tijolo por tijolo, diminuem-se preconceitos e comportamentos antiéticos arraigados historicamente na alma brasileira.

No entanto, são necessárias outras iniciativas que não se limitem exclusivamente às palavras e ao discurso racional. O cientista social também necessita de métodos mais ativos de intervenção na sociedade. Voltando à noção de catarse proveniente do teatro, temos a valiosa contribuição de Augusto Boal (1977), com o "Teatro do Oprimido", deveras atual para o Brasil. Desenvolvido em plena época de ditadura militar, as ruas, as instituições e as comunidades, por meio desse teatro, exprimiam o enorme sofrimento pela voz do povo, que sangrava em silêncio político.

Outro destaque metodológico que remete à experiência da catarse é o teatro espontâneo criado por Jacob Levy Moreno (Moreno, 1984). A participação no teatro espontâneo é a do sujeito que se torna autor de seu próprio drama, ou do grupo que representa seu drama, por meio de um protagonista ou dele próprio.

Segundo Moreno (1975), a catarse promovida do teatro espontâneo é a catarse de integração. $\mathrm{O}$ autor nos diz:

A teoria psicodramática desenvolveu a idéia de catarse em quatro direções: a somática, a mental, a individual e a grupal. (...) na situação psicodramática, o paciente recebe as três formas básicas de catarse mental, uma no autor - criador e paciente do drama privado - a outra no ator que lhe dá vida e a terceira no público que co-sente os acontecimentos (...) Pela integração sintética de todos os elementos, pode ser obtida a catarse total (pp. 65-6).

A catarse de integração vivifica a subjetividade por meio da espontaneidade (fator "e"). Espontaneidade é a capacidade de dar respostas novas a problemas antigos ou adequadas a problemas novos. É o fator sociopsíquico primário e faz o homem sobreviver, desde o nascimento. Para Moreno (1975), toda produção criativa é catalizada pelo fator " $\mathrm{e}$ ". A espontaneidade é o pólo oposto da conserva cultural. Ambas estão num continuum. A conserva cultural é o produto de uma sociedade, caracterizado pela arte, mitos, costumes etc. Em termos individuais, a 
conserva está presente nas expressões e condutas conservadas, que se mantém ao longo da história do indivíduo. No entanto, em sua origem, a conserva cultural é gerada pela própria espontaneidade. A catarse de integração, portanto, libera o homem rotulado, robotizado, padronizado, submetido às intempéries dos donos do poder e de seus próprios boicotes inconscientes.

O teatro espontâneo deu origem aos métodos sociátricos. A partir desses métodos, Moreno a socionomia (Moreno, 1974). Trata-se de uma ciência aberta, em pleno desenvolvimento, que apregoa a interdisciplinaridade para intervir no sofrimento humano multicausal e complexo. O desenvolvimento dos estudos socionômicos de Moreno (1974) resultou na sociatria, ou o tratamento dos grupos doentes. Nessa definição, Moreno ainda era influenciado por uma visão sociopsicopatológica, de acordo com modelo médico-biológico antigo. Porém, atualmente, redefine-se esse enfoque de acordo com uma visão complexa: sociatria é um conjunto de métodos terapêuticos para tratamento de grupos em sofrimento ou em conflito desagregador. $\mathrm{O}$ autor visava a uma nova ordem mundial terapêutica ou à superação das ideologias comunistas e capitalistas, perseguindo a convivência humana dentro de valores cosmodinâmicos que promulgassem o bem- estar tanto individual como coletivo. As propostas de Moreno, apesar de terem algumas reminiscências de modelos arcaicos, adiantaram concepções hoje apregoadas pelas teorias da complexidade de Morin (2000), dos fenômenos ocultos de Capra (2002), dos campos mórficos de Sheldrake (1999) e da terapia construcionista de McNamee e Gergen (1995).

O sociodrama, portanto, é um dos métodos sociátricos para abordar os conflitos, as crises ou os sofrimentos de um grupo ou da comunidade. No sociodrama e nos demais métodos sociátricos, o efeito terapêutico surge da catarse de integração dos papéis sociais que são representados num palco específico, tornando-se papéis sociodramáticos. Nesse espaço para a ação, há uma realidade suplementar propiciadora de um texto único, in status nascendi, de um sujeito-protagonista, que será autor e ator de sua vida em refazimento e em revisão. No entanto, o indivíduo refaz-se e se revê no processo relacional. Não há papel social, nem papel sociodramático, sem o papel complementar. Então, a catarse de integração pressupõe o ser-humano-em-relação, ou seja, pressupõe vínculo, grupo e intersubjetividade.

Segundo Moreno (1975):

O verdadeiro sujeito do sociodrama é o grupo. (...) Há conflitos nos quais estão envolvidos fatores coletivos (...) supra-individuais (...) e que têm que ser compreendidos e controlados por meios diferentes. (...) podese, na forma de sociodrama, tanto explorar como tratar, simultaneamente, os conflitos que surgem entre duas ordens culturais distintas e, ao mesmo tempo, pela mesma ação, empreender a mudança de atitude dos membros de uma cultura a respeito dos membros da outra (pp. 413-415).

No sociodrama, tecnicamente, o diretorpesquisador segue as etapas propostas por Moreno $(1974,1975)$ para que todos os membros do grupo se mobilizem e participem do evento. As etapas são: 1) aquecimento: fase de preparação dos participantes para ativamente refletirem ou vivenciarem os temas a serem tratados; 2) dramatização: etapa do auge da polêmica, da discussão ou da vivência por meio de cenas dramáticas representadas pelos membros do grupo. Essa etapa visa à compreensão fenomenológica do conflito e às tentativas de resolução do mesmo; 3) comentários: momento em que
Não há papel social, nem papel sociodramático, sem o papel complementar. 
os participantes analisam as repercussões do evento sobre eles e o diretor-pesquisador lhes dá um feedback sobre a participação; 4) processamento teórico: momento em que o diretor faz a leitura socionômica de alguns resultados alcançados e uma análise sociocultural.Cada sessão sociodramática é única e o diretor pode utilizar vários tipos de procedimentos e recursos técnicos para atingir as etapas do encontro.

No sociodrama, os sujeitos do grupo atualizam papéis que estão em estado potencial. Os sujeitos encontram personagens espontâneo-criativos que expressam e dinamizam os estados co-conscientes e coinconscientes. Esses estados são as trocas interpsíquicas que fornecem ao grupo dinâmicas e características que the são peculiares.

Moreno (1983) afirma:

O dilema a ser superado é a antítese natural entre o inconsciente individual (e coletivo) de A e o inconsciente individual (e coletivo) de B. (...) Pessoas que vivem numa íntima simbiose, como mãe e filho (...), desenvolvem ao longo do tempo um conteúdo comum, ou o que poderia ser chamado de "COinconsciente" (p.65).

Esses conteúdos inconscientes são compartidos, com-partilhados, e são resultado da co-autoria das tramas manifestas e ocultas existentes entre as pessoas.

O método sociodramático visa ao intercâmbio consciente e inconsciente que resulta na co-criação (Aguiar, 1998; Perazzo, 1994). A co-criação é a complementação de papéis sociais que proporciona o bem-estar grupal. Segundo Nery (2003), a Socionomia se especializa no entendimento dos fenômenos da co-criação e da interpsique. Portanto, a encenação de conflitos sociais e políticos leva as pessoas a co-criarem e a viverem a catarse de integração, numa perspectiva de entendimento e de desenvolvimento social.
Para Kellerman (1998), "A administração dos conflitos se transforma numa tarefa que é, no mínimo, tão importante quanto ajudar os sobreviventes a lidar com suas experiências traumáticas" (p. 52). O autor aponta o sociodrama como um dos recursos do terapeuta de grupo para essa tarefa e apresenta três tipos de aplicações, a saber: 1) sociodrama da crise, 2) político e 3) da diversidade. O sociodrama da crise tem o foco social sobre o trauma, a teoria social é a da adaptação e o ideal social é a homeostase. Busca-se ajudar o grupo a enfrentar melhor as tensões sociopsicológicas e a encontrar novo equilíbrio social. O sociodrama político tem o foco social sobre a desintegração; a teoria social é a do conflito e o ideal social é a igualdade. O tema é a desintegração social, a estratificação e a desigualdade como manifestações de conflitos socioeconômicos. Busca-se impulsionar a sociedade na direção de maior justiça e eqüidade sociais. O sociodrama da diversidade trabalha com conflitos advindos de estereótipos, preconceitos, racismo, intolerância, estigmatização e/ou atitudes negativas contra pessoas por serem diferentes. Busca-se transcender as diferenças que freqüentemente compartimentalizam a humanidade em grupos mutuamente exclusivos e isolados.

Os sociodramas são realizados no mundo todo: Dalmiro Bustos, por exemplo, dirigiu sociod́ramas na Argentina, durante a Guerra das Malvinas; Márcia Karp, na mesma época, realizou alguns na Inglaterra, e Mônica Zuretti, na Alemanha, no período das eleições de extremistas de direita (Kellerman, 1998). No Brasil, em 2002, a Prefeita de São Paulo, Marta Suplicy, com a colaboração de Marisa Greeb, convidou psicodramatistas para realizar sociodramas na cidade, objetivando a participação dos cidadãos nas propostas de resoluções dos problemas encontrados. Esse foi um dos maiores eventos sociodramáticos do mundo (Cesarino, 2004). Quanto às pesquisas, destacamos o trabalho de Ana Maria Zampiere (1998), que realiza 
139

sociodrama construtivista da Aids com casais heterossexuais, cujo resultado tem sido a maior prevenção da Aids nos chamados vínculos monogâmicos, e Maria Rita D’Angelo Seixas (1992), que privilegia a terapia familiar com o método sociodramático sistêmico, ao trazer para o palco, por meio dos papéis familiares, os personagens e os conteúdos ocultos, que desintegram a família.

A intervenção sociodramática exige compreensão teórica do funcionamento dos grupos e da sociedade. Os grupos, mantendose suas especificidades, em alguns aspectos, podem ser compreendidos tal como os analistas sociais entendem a estrutura social. A estrutura social é ambivalente, contraditória e dialética (Levy, 2001; Demo, 2000; Freire 1976). Moreno (1974), ao considerar o grupo um microcosmo que representa (ou reflete) o macrocosmo da sociedade, aponta as contradições e ambivalências grupais, advindas das relações de poder, desigualdades, processos dinâmicos e padrões comportamentais.

Essas características do socius demonstram que o processo de mudança é uma construção subjetiva e intersubjetiva, patente nos discursos dos indivíduos, nas ações, nas interações e no desenvolvimento grupal. A mudança exige ampliações constantes de consciência, visualização da realidade, percepção do que nela está oculto e do que está além dela, mas a ampliação de consciência sem o mundo emocional que impulsiona a ação para o desconhecido, eliminando medos e apegos, pouco resultado traz.

No trabalho com grupos, observa-se que o processo de mudança incorpora repetições: condutas, discursos e emoções, ao se repetirem, trazem, paradoxalmente, algo novo e surpreendente, por mais que os membros queiram o mesmo. Nas dinâmicas e padrões interacionais, há repetição em espiral e repetição circular (Motta, 1994). A repetição em espiral promove a mudança por meio de nossa liberdade, advinda da espontaneidadecriatividade que refaz a visão de mundo, reorientando nossas ações. A repetição circular nos faz continuar no conformismo de uma homeostase sociopsíquica ou no sofrimento determinado pela nossa história.

No entanto, chega o "instante" do herói, do profeta, do protagonista que agoniza, clama e luta por mudanças para si e para o grupo (Moreno, 1975). Nesse momento, suas ações não estão aprisionadas na "resistência" e nas "inter-resistências", nos medos, na insegurança em relação ao novo, ao desconhecido, ao não familiar. Suas ações direcionam-se para a transformação de um status quo relacional, grupal, institucional e social. É a voz do drama coletivo representado num drama individual que reconstrói, por exemplo, o caminho dos privilégios de uma elite ou de um sistema patriarcal.

Diversos protagonistas surgiram dos movimentos sociais no Brasil clamando por políticas e ações afirmativas. O conceito de ação afirmativa surgiu na legislação brasileira em 1931 e em dispositivo incorporado à CLT para assegurar o direito do trabalhador brasileiro ao emprego perante a mão de obra imigrante. As políticas e ações afirmativas foram criadas para aplacar o déficit histórico de cidadania das minorias no Brasil. Segundo Pinho (2003),

Ação afirmativa é a utilização de mecanismos de proteção e favorecimento aos que necessitem de uma especial tutela, como uma forma de superação das diversas desigualdades existentes em uma sociedade (p. 102).

Na década de 1960, nos Estados Unidos, líderes como Martin Luther King
No trabalho com grupos, observa-se que o processo de mudança incorpora repetições: condutas, discursos e emoções, ao se repetirem, trazem, paradoxalmente, algo novo e surpreendente, por mais que os membros queiram o mesmo. 
impulsionaram os movimentos em prol dos direitos civis, resultando em formulação de leis antidiscriminatórias que originaram a Ordem Executiva 11.746, na qual aparece a expressão "Affirmative Action". Essa expressão referia-se às medidas que visavam ao tratamento diferenciado das instituições em favor de alguns segmentos sociais. O Brasil sempre buscou acompanhar o movimento em prol dos direitos civis no mundo e, em 1958, ratificou a Convenção Internacional sobre a eliminação de todas as formas de discriminação racial. O País tentou incorporar, às suas instituições, normas relativas aos direitos humanos previstas nos tratados internacionais. Foram implantadas políticas afirmativas semelhantes às dos EUA a partir da década de 1990. Dentre outras medidas, houve políticas de incentivo à cultura negra, de sistemas de cotas para negros nos meios de comunicação e nas empresas públicas e privadas. No entanto, somente em 1996, as ações afirmativas receberam maior impulsão com a elaboração do Programa Nacional de Direitos Humanos (Gomes, 2003).

A Constituição Federal de 1988 foi o produto da consciência crítica ampliada pelo processo de redemocratização a partir da década de 1980. O preâmbulo da Constituição do Brasil reza por um país democrático, igualitário e justo. O artigo 5o explicita esse prelúdio, afirmando que todos são iguais perante a lei. A Constituição é ainda um espectro do desejo de uma realidade social brasileira justa e digna.

Esse quadro político-jurídico e a realidade estatística de exclusão do País, em que a raça negra tem uma longa história de diferença em relação aos brancos quanto à oportunidade de acesso à universidade pública, trouxe sérias preocupações para intelectuais e grupos sociais. Nos últimos cinco anos, algumas universidades brasileiras iniciaram o debate para a implantação do sistema de cotas para negros. A Universidade de Brasília, ao se certificar que a desigualdade racial em relação a estudantes é notória - dos 26 mil alunos, apenas $2 \%$ são negros - iniciou amplo debate democrático sobre o tema. Esses debates impulsionaram o Conselho de Ensino, Pesquisa e Extensão, no dia 06 de junho de 2003, a aprovar o Projeto de Cotas Para Negros, que deverá ser implantado a partir de 2004 (Carvalho \& Segato, 2002). O Projeto foi criado pelos professores do Departamento de Antropologia da UnB, José Jorge de Carvalho e Rita Segato. Segundo os membros da comissão, o Plano de Cotas Para Negros privilegia o ataque à discriminação não apenas social, mas racial.

A implantação do sistema de cotas para negros faz parte de um drama social que promove a ação impregnada da expansividade afetiva do indivíduo em relação ao socius. Essa política permite um processo de mudança grupal em que, a partir de uma leitura socionômica, esperam-se os seguintes movimentos grupais: os membros do grupo vivem inicialmente a indiferenciação, momento no qual a comunicação é exígua, os indivíduos estão isolados, possuem idéias vagas sobre o tema, mas ainda não têm ou não se permitem ter chances de conhecer as posições dos demais, quase não há trocas, e os indivíduos pouco se identificam. Em seguida, avançam em seus processos grupais para as diferenciações horizontais, nas quais os membros se percebem em um grupo e começam a agir de acordo com as propostas comuns, comparando seus pontos de vista com os dos demais, cedendo ou coagindo, passando a permitir que as idéias dos demais interajam com as suas, e seguem suas interações evoluindo para as diferenciações verticais. Nestas, os diversos papéis sociais e latentes 
começam a ser complementados, trazendo lideranças e subgrupos. Nesse momento, cada indivíduo e o grupo experimentam novas possibilidades de se perceber e de enfrentar a realidade.

Para melhor conhecer o impacto de tais políticas na visão dos alunos da Universidade de Brasília e no intuito de ilustrar o potencial de mobilização e transformação social do sociodrama, as autoras aproveitaram o momento universitário para realizar um sociodrama sobre o sistema de cotas para negros. A demanda dessa atividade também surgiu dos alunos de uma turma do Curso de Psicologia do Instituto de Psicologia. O evento - dirigido por uma psicodramatista convidada (diretora) e pela professora da disciplina (egoauxiliar) $^{1}$ - ocorreu no dia 16 de junho de 2003, teve duração aproximada de duas horas e, a título de ilustração, passamos a descrevê-lo.

No aquecimento inicial para a atividade temática, realizou-se um jogo dramático que possibilitou a vivência da exclusão social. O jogo dramático consistia em proporcionar a poucos estudantes a oportunidade de usufruir de algumas vantagens, tais como chocolates, água, refrigerantes, ver um objeto inusitado, etc. Os demais estudantes ficavam pedindo, querendo usufruir. Dois estudantes eram os "representantes do governo" que diziam que todos iriam ter acesso àquelas vantagens, mas só depois de um tempo. Os alunos criaram diálogos a partir dos personagens que emergiram e exprimiram sentimentos de exclusão e indignação. A partir dos comentários desse jogo, iniciou-se o sociodrama com a questão: "Quem é a favor, quem é contra o sistema de cotas para negros nas universidades?"

A diretora do sociodrama pediu que a turma se dividisse em quatro subgrupos: dois favoráveis e dois desfavoráveis ao sistema de cotas para negros nas universidades. A divisão em grupos menores deu-se em função de sua propriedade de favorecer a participação de todos, evitando a dispersão grupal. Após a solicitação da subdivisão da turma, foram formados três subgrupos: um favorável ao sistema de cotas, formado por quatro integrantes (três negros e um branco), e dois contra o sistema (formados, respectivamente, por 12 e 11 integrantes, totalizando 23 alunos, todos brancos). A partir das subdivisões produzidas pelas respectivas escolhas, observou-se que a maioria dos alunos posicionou-se de forma desfavorável ao sistema de cotas. Diante do reduzido número de alunos favoráveis, formou-se apenas um grupo de alunos favoráveis.

A proposta seguinte foi a de que os grupos invertessem seus papéis. Nessa tarefa, pediuse que os integrantes dos subgrupos se colocassem no lugar daqueles que defendem pontos de vista contrários aos seus e que, dessa forma, argumentassem quanto à política de cotas. Depois disso, foi solicitado a um representante de cada grupo que expusesse a produção do seu subgrupo.

A inversão de papéis é uma técnica psicodramática que possibilita a experiência de se imaginar no lugar do outro a partir das sugestões que o diretor faz aos participantes para que se aqueçam nesses papéis.

Após a exposição dos argumentos pelos representantes, os subgrupos foram dissolvidos, cada aluno voltou a assumir seu papel originário e houve um debate do tema em plenária (fase correspondente ao compartilhar).

Embora não houvesse um equilíbrio entre o número de alunos favoráveis e desfavoráveis, a vivência do papel antagônico produziu
A inversão de papéis é uma técnica psicodramática que possibilita a experiência de se imaginar no lugar do outro a partir das sugestões que o diretor faz aos participantes para que se aqueçam nesses papéis. 
argumentos que geraram discussões qualitativamente relevantes e mobilizadoras, sintetizadas abaixo.

Argumentos a favor: "as cotas recompensam os negros tão discriminados ao longo da história do País"; "as cotas pretendem saldar uma dívida para com os negros do País"; "as cotas podem facilitar o acesso ao conhecimento, ao mercado de trabalho e a uma melhor distribuição de renda"; "as cotas podem ajudar na auto-estima dos negros"; "o País precisa se conscientizar do sofrimento dos negros".

Argumentos desfavoráveis: "as cotas não atingem a raiz do problema, que é a questão de educação para todos"; "o problema não é uma questão de cor e, sim, de pobreza"; "o negro vai ser mais discriminado com o sistema de cotas"; "a qualidade de ensino vai piorar muito com a entrada de pessoas despreparadas"; "a universidade vai ficar marrom"; "quem sofre é o pobre!"; "os negros já têm acesso ao ensino público para todos!"; "não vejo o negro. Afinal, quem é negro no País?"

As falas remeteram a temas que foram agrupados em algumas categorias:

"Trata-se de processo de exclusão". Argumentou-se que essa política é perversa, exclui o indivíduo que se prepara para o vestibular e é determinada por uma elite de pessoas que detém o poder.

"É uma política paliativa". Avaliou-se que há um risco de reforçamento social da "vitimização" do negro, que, em sua maioria, vive um processo de auto-exclusão social. Políticas mais efetivas propõem a educação pública fundamental de qualidade, que garantam a oportunidade de acesso para todos na universidade.

- "É o momento para enfrentar da realidade da discriminação racial". Afirmou-se que o processo de implantação de cotas deixa mais manifesto o preconceito racial no País, cuja maioria da população se diz não discriminadora. O preconceito é sutil, mas é visível nas representações dos negros nas universidades, nos empregos de gerenciamento e de altos escalões governamentais.

- "É política que garante a oportunidade de inclusão social". Argumentou-se que pode ser uma política provisória, que dará a oportunidade para que a universidade tenha mais negros e, a partir daí, lhes favoreça o acesso ao ensino público superior ou à qualificação técnica. Indiretamente, trata-se de uma oportunidade para a "classe pobre" ter acesso à universidade, pois aquela é constituída, em sua maioria, de negros.

"Pode-se, por meio das cotas, retratar a história dos danos econômicos, sociais e psíquicos causados aos negros no País". Pontuou-se que é o momento histórico propício para a reparação dos sofrimentos causados aos negros desde seus ancestrais, em nosso país.

Ao longo do evento, a diretora questionou os sentimentos dos participantes. Prevaleceram sentimentos de agonia, ansiedade frente ao tema, tristeza, medo de aumentar o preconceito, indiferença, choque e indignação diante da quantidade de colegas desfavoráveis às cotas, desejo de compreensão do outro que é diferente e injustiça social.

O sociodrama é também uma metodologia de pesquisa ativa, caracterizada por um 
143

Maria da Penha Nery \& Maria Inês Gandolfo Conceição

processo dialógico, com intensa troca de conteúdos psíquicos e atitudinais entre as pessoas. Os dados do sociodrama advêm 1) de variáveis sociométricas, por exemplo, o modo como os subgrupos se constituem, os tipos dos subgrupos; 2) da sociodinâmica, composta pelos sentimentos e falas presentes na ação dos personagens em relação à polêmica e 3) tipos de cenas e conflitos, atuação dos protagonistas e participação no compartilhamento final. As análises desses dados contribuem para a compreensão dos estados co-conscientes e co-inconscientes do grupo.

O sociodrama realizado na UnB demonstrou tramas presentes nos estados co-consciente e co-inconsciente do grupo, por meio dos seguintes dados: 1) a cena inicial da subdivisão grupal expôs uma geografia que estava oculta, desvelando que todos os participantes brancos eram contra a implementação do sistema de cotas; 2) o subgrupo dos favoráveis, todos negros, ficou chocado e indignado com essa constatação. Um dos participantes reagiu exigindo que houvesse dois representantes na defesa de suas argumentações, pois queria ter igualdade de condições no debate, já que havia dois subgrupos contrários aos seus argumentos. Outro participante, emocionado - um negro relatou a história da desigualdade racial no País, resgatando a trajetória de vida de seus próprios ancestrais; 3) a ambigüidade permeou as falas, exacerbando o clima emocional relacionado à agonia e à ansiedade geradas pelo tema; 4) alguns participantes brancos expuseram que a indiferença do branco, que torna invisível a desigualdade racial na sociedade, estava refletida naquele evento.

A sociodinâmica refletiu que os membros do grupo estavam, inicialmente, isolados e indiferentes. O debate começou com participações esporádicas dos membros. $\mathrm{O}$ participante negro que relatou sobre a história da desigualdade no País se tornou o protagonista, pois o grupo direcionou toda sua atenção a ele e respondeu-lhe, manifestando surpresa quanto à permanência desse processo no País. Esse movimento relacional contribuiu para a proposta da inversão de papéis. O grupo alcançou maior troca comunicacional, conseguindo avançar para as diferenciações horizontais, e alcançou a diferenciação vertical quando novas lideranças de participantes negros e brancos se manifestaram no evento.

O processo imaginário da inversão de papéis aprofundou a discussão e contribuiu para a promoção de novas atitudes em relação ao tema, dentre elas: "nunca tinha parado para pensar no tanto que o acesso à educação para o negro é prejudicado"; "poucos são os negros que se sobressaem no País e, quando chegam a posições de destaque, foi com muito sofrimento"; "eu era contra o sistema de cotas, mas agora já não sei o que sou"; "eu sei o que é ser discriminado, mas ainda não consigo ser a favor das cotas"; "isso mexeu comigo... vi o quanto o negro era invisível"; "é importante que nós, da Psicologia, possamos discutir essas questões"; "agora entendi porque fiquei impressionada quando vi que só os negros da sala foram a favor dessa política afirmativa".

A técnica da inversão de papéis, nesse contexto, facilitou a superação do discurso racional baseado em conservas culturais que identificam os indivíduos por meio de traços estereotipados que realçam as desigualdades, excluindo as igualdades. Portanto, a transição da ordem das singularidades físicas, sexuais, genéticas ou outras para a ordem ética e moral (Silva, 2004) é favorecida com o sociodrama. O sociodrama contribuiu para a inclusão 
social, pois o processo co-construtivo, a produção coletiva, a partir de um tema, permitiu interações espontâneas e criativas. A co-construção, visível na sociodinâmica dessa atividade, deu espaço para a subjetividade se expressar e tornou visível a diferença racial e o poder socioeconômico do branco no País. Essa intersubjetividade incrementa a democracia e a emancipação de cada um.

O sociodrama realizado na Universidade de Brasília alcançou a catarse de integração quando o compromisso participativo se exacerbou, a partir da proposta da técnica de inversão de papéis. Muitos atores, ao refletirem a questão sob o ponto de vista do outro, refizeram crenças e noções conservadas de seus papéis originais. A catarse é também notória quando a maioria da turma considerou o sociodrama um alerta para as questões da discriminação social e manifestou o desejo de luta por políticas de afirmação social mais efetivas no País, o que demonstra que houve novas percepções de si, do outro e a ampliação da consciência sócio-política dos participantes.

Ao final do evento, alguns membros desfavoráveis às cotas para negros nas universidades manifestaram que a discussão trouxe novas formas de ver a questão; para outros, foram despertadas atitudes mais favoráveis à implantação do sistema.

A política de cotas para negros, assim como outras tantas políticas afirmativas, tem a função majestosa de fomentar o debate sobre o sofrimento das minorias e de incrementar a luta dos excluídos socialmente. Uma política afirmativa desfavorecedora dos privilégios e status quo das elites brasileiras acarreta diversos conflitos, como os apresentados pelas categorias levantadas no sociodrama.

Essa atividade pode ser caracterizada como um misto de sociodrama da diversidade e político, pois houve a produção coletiva a partir de um tema relacionado a processos discriminatórios históricos vividos pelo País em relação aos negros.

No Brasil, a demanda social é visível a todo instante. Faz-se mister que o psicólogo e o profissional de ciências sociais e humanas favoreçam as transformações sociais com consciência crítica e instrumentos teóricos e técnicos adequados. A psicologia traz a importância da subjetividade e da intersubjetividade na transformação social. O uso do método sociodramático promove uma troca interpsíquica específica, que contribui para as redefinições de verdades e crenças tão arraigadas e mantenedoras do sistema de injustiça social. Uma delas é o quanto se extrai de miséria sociopsíquica dos privilegiados que abusam do poder.

O sociodrama nas instituições e na comunidade fomenta práticas de convívio e de poder libertadoras do homem oprimido ou marginalizado. Trata-se de criar oportunidade para o indivíduo e para o grupo se encararem frente a frente, se expressarem e viverem seus conflitos na busca do bemestar social. A inversão de papéis - técnica sociátrica fundamental - favorece o resgate da ética humana, pois é um convite a se colocar na pele do outro: pele do corpo e da alma, com todas as suas cores, seus sabores e dissabores. 
AGUIAR, M. Teatro Espontâneo e Psicodrama. São Paulo: Agora, 1998.

ARISTÓTELES. Poética. Barcelona: Editorial Bosch, 1985.

BOAL. A. Teatro do Oprimido e outras Poéticas Políticas. Rio de Janeiro: Civilização Brasileira, 1977.

CAPRA, F. As Conexões Ocultas. São Paulo, Cultrix, 2002.

CARVAlHO, J.J. \& SEGATO, R.L. Uma Proposta de Cotas para Estudantes Negros na Universidade de Brasília. Disponível em: $<$ www.unb.br/ics/dan/Serie314empdf $>$. Acesso em: $15 \mathrm{fev}$, 2004.

CESARINO, A.C. Psicodrama na Rua. Disponível em: $<$ www.psicodramadacidade.com.br/cesarino.htm > Acesso em: 9 mar, 2004.

DEMO, P. Globalização da Exclusão Social. Ser Social v. 4, 1999, pp. 43-74.

FOUCAUlT, M. Microfísica do Poder. Rio de Janeiro: Graal, 1990.

FREIRE, P. Ação Cultural para a Liberdade e outros Escritos. Rio de Janeiro: Paz e Terra, 1976.

FREUD, S. Três Ensaios sobre a Teoria da Sexualidade. Rio de Janeiro: Imago (1905) 1969, v. 7. (Standart Brasileira, Obras Completas).

GOMES, J.B. B. Ação Afirmativa e Princípio Constitucional da Igualdade - o Direito como Instrumento de Transformação Social. Rio de Janeiro: Renovar, 2003.

IBGE - Instituto Brasileiro de Geografia e Estatística. Disponível em: <www.ibge.gov.br>. Acesso em 15 nov, 2003.

IPEA - Instituto de Pesquisa Econômica Aplicada. Disponível em: <www.ipea.gov.br>. Acesso em 20 de out. de 2003.

KELLERMAN, P.F. Sociodrama. Revista Brasileira de Psicodrama, 8, 1998, pp. 51- 68 .

LEVY, A. A Mudança: esse Obscuro Objeto do Desejo. In M.N.M. Machado, M.N.M.; Castro, E.M.; Araújo, J.N.G.; Roedel, S. (org.). Psicossociologia, Análise Social e Intervenção. Belo Horizonte: Autêntica, 2002, pp. 37-49.
MCNAMEE, S. \& GERGEN, K.J. (org.). A Terapia como Construção Social. Porto Alegre: Artes Médicas, 1995.

MORENO, J. L. Psicoterapia de Grupo e Psicodrama. São Paulo: Ed. Mestre Jou, 1974.

Psicodrama. São Paulo: Cultrix, 1975. Summus, 1983.

Fundamentos do Psicodrama. São Paulo:

Summus, 1984.

O Teatro da Espontaneidade. São Paulo:

MORIN, E. Os Sete Saberes Necessários à Educação do Futuro. São Paulo: Cortez/Unesco, 2000.

MOTTA, J. M. C. Jogos: Repetição ou Criação? Abordagem Psicodramática. São Paulo: Plexus, 1994.

NERY, M.P. Vínculo e Afetividade - Caminhos das Relações Humanas. São Paulo: Agora, 2003.

PERAZZO, S. Ainda e sempre Psicodrama. São Paulo: Agora, 1994.

PINHO, R. C. R. Teoria Geral da Constituição e Direitos Fundamentais. Vol. 17, 4o Ed Rev. São Paulo: Saraiva, 2003.

REÑONES, A.V. Cartase de Integração: uma Pequena Viagem Etimológica-conceitual. Revista Brasileira de Psicodrama, 4, 1996, pp. 35-48.

SEIXAS, M.R. D. Sociodrama Familiar Sistêmico. São Paulo: Aleph, 1992.

SILVA, S.G. Preconceito no Brasil Contemporâneo: as Pequenas Diferenças na Constituição das Subjetividades. Disponível em: <revistacienciaeprofissao.org >. Acesso em: 10 mar, 2003.

SHELDRAKE, R. Sete Experimentos que Podem Mudar o Mundo. São Paulo: Cultrix.

ZAMPIERE, A M F. O Sociodrama Construtivista. Revista Brasileira de Psicodrama, 8, 1998, pp.81-7.
Referências 